\title{
Animal abuse and intimate partner violence: Researching the link and its significance in Ireland - a veterinary perspective
}

\author{
Gallagher, B. ${ }^{1}$, Allen, M. ${ }^{2}$ and Jones, B. ${ }^{1}$ \\ ${ }^{1}$ UCD School of Agriculture, Food Science and Veterinary Medicine, University College Dublin, Belfield, Dublin \\ 4, Ireland \\ 2 UCD School of Applied Social Science, University College Dublin, Belfield, Dublin 4, Ireland
}

\begin{abstract}
Research on domestic violence has established a substantial association between intimate partner abuse and the abuse of children within the home. It is only recently however, that researchers have demonstrated the correlation between non-accidental injury in animals, and abuse of women by their intimate male partners. A growing body of evidence suggests that animal abuse can be an early indicator for other forms of violent behaviour. This research includes the responses of a sample of 23 women using refuge services in the Republic of Ireland. It investigates the connection between domestic violence and animal abuse, and ascertains if there is sufficient support service for animals and people relevant to domestic abuse. In the survey population, 57\% of women reported witnessing one or more forms of abuse, or threats of abuse, of their pets. Five of which were reported to have resulted in the death of the pet. Eighty seven per cent of women felt a facility to accommodate pets would have made their decision to leave the family home easier. Four women disclosed that lack of such a service and concern for the welfare of their companion animals caused them to remain in their abusive relationships for longer than they felt appropriate. Nine families placed pets in the care of family or friends, one woman is unaware of the fate of her pet, while the pets of six families remained with the abusive male after his partner entered a refuge. The majority of women felt unable to talk to anyone about their fears for their pets' welfare. Many felt that there is no service which can provide temporary accommodation for womens' pets while they are in refuge. The results obtained support those found elsewhere in larger studies in the USA and UK, and demonstrate an association of animal abuse in households where there is reported domestic violence.
\end{abstract}

Keywords: animal abuse, cat, dog, domestic violence, non-accidental injury

\section{Corresponding author:}

\section{Boyd Jones}

UCD School of Agriculture, Food Science and Veterinary Medicine,

University College Dublin, Belfield, Dublin 4, Ireland

E-mail: boyd.jones@ucd.ie

Tel: +3531716 6103
Irish Veterinary Journal Volume 61 Number 10 658-667, 2008
A number of recent studies have highlighted the relationship between non-accidental injury (NAI) in animals (also known as 'battered pet syndrome') and domestic violence (Kellert \& Felthouse, 1985; Arkow, 1996; Ascione, 1999; Flynn, 2000). Further research identifies that intimate partner violence, abuse of children and abuse of companion pets tends to occur in the same families (DeViney et al., 1983; Arkow, 1992, 1994; Boat, 1995; Ascione, 1999; Flynn, 2000; Faver \& Strand, 2003). Flynn (2000) found that $46.5 \%$ of women using a refuge in South Carolina reported that their abuser had either harmed or threatened to harm their pets. Other studies have suggested a higher prevalence. Ascione (1998) demonstrated that almost two-thirds of women who suffered domestic violence also witnessed abuse of, or threats to, their pets. A study in the United Kingdom identified similar statistics, with $66 \%$ of women in one survey reporting threats, and $38 \%$ reporting actual abuse of their pet (Marsden, 1997). This data indicates that animal abuse in the context of interpersonal violence is likely to be more prevalent and universal than was previously realised. While it is likely that similar patterns of multiple forms of abuse can be found in Ireland, no Irish study has examined this aspect of intimate partner violence.

The purpose of this study, undertaken by veterinary practitioners and a social worker, was to examine the 'link' between domestic violence and animal abuse in Ireland, and to establish to what extent the abuse of pets is used to control women within an abusive relationship. In doing so, the aim is to raise awareness of the 'link' amongst the staff of women's refuges, social workers, childcare workers and veterinary practitioners.

\section{Domestic violence}

Official Irish statistics place reports of violence against women within European and US figures, with the only Irish national prevalence study to-date (Kelleher and O'Connor, 1995) showing that $18 \%$ of women had, at some time in their lives, been victims of emotional, sexual or physical violence, or subject to threats of violence, and had their property or pets damaged, by male intimate partners. European Union figures show that $25 \%$ of women have experienced abuse by a male intimate (EWL, 2004). 


\section{The role of control and coercion in domestic violence}

There have been ongoing debates in literature on the aetiology and purpose of violence within the family (Strauss and Gelles, 1990; Dobash and Dobash, 1992; Stark and Flitcraft, 1996; Gelles, 1997; Kimmel, 2002), particularly the role of control and coercion (Johnson and Ferraro, 2000). The feminist understanding of domestic violence has been clear in emphasising the centrality of power, and the dynamics of power and control in any comprehensive understanding of violence against women by male intimates. Pence and Paymar's (1987) well known Power and Control Wheel lists a range of 'tactics' which male intimates use to control their female partners, including economic control, intimidation, isolation and threats. Bradley et al. (2002) made clear that fear of one's partner and experiencing controlling behaviour are significantly associated with domestic violence.

\section{Animal abuse}

Animal abuse has been defined as "the intentional harm of an animal”, and may involve physical abuse, sexual abuse or neglect. It includes, but is not limited to, wilful neglect, inflicting injury, pain or distress, or malicious killing of animals (Munro and Thrushfield, 2001). Physical abuse encompasses kicking, punching, throwing, burning, microwaving, asphyxiation and the administration of drugs or poisons. Sexual abuse involves the use of the animal for sexual gratification. Neglect is a failure to provide food, water, shelter, companionship or veterinary attention. According to the RSPCA in the UK, there were $1,279,953$ complaints of cruelty to animals in 2003, and 708 convictions resulted from 105,932 investigations. There are, however, no comparable figures are currently available for the Republic of Ireland (ROI).

\section{Materials and methods}

The study was carried out with the help of 23 women who were currently using, or had recently stayed in, a refuge in the ROI. One refuge was in Dublin, while the others were located in two smaller cities in the Republic. A pilot questionnaire was designed and distributed to the refuge directors for their input and approval of content. The finalised questionnaire (available upon request) was designed to obtain information in a sensitive, non-threatening manner. Prior to distribution of the questionnaires, the staff at each refuge took part in a group discussion on current theories on the link between animal abuse and domestic violence. To ensure protection and confidentiality for the women who would participate, each refuge needed to be able to guarantee provision of supportive counselling for those willing to complete the questionnaire. This commitment was necessary as some questions were sensitive with the potential to revive painful memories. The questions requested information on:

- their experiences of abuse of their pet(s);

- the nature of the threats and/or abuse;
- whether children experienced abuse to pets;

- their perceived motivation for the abuse by their intimate partner;

- the effects of abuse on them and their family;

- support services available to them;

- the availability of animal support services; and,

- their response if support services were available.

There was also a free communication section where women were able to write what they wished concerning their experiences of abuse; to them and and their pets. The women who agreed to participate in the study were invited to complete the questionnaire. In order to facilitate those with literacy problems, each woman participating in the study was offered assistance in completing the questionnaire either by refuge staff or by the researcher. A reminder letter and free post envelope was sent to each of the three refuges involved, to encourage return of the completed questionnaires.

The total sample size from the three refuges was 23 , of which 19 participants were chosen at random, and four were identified by staff of the refuges. As the purpose of the study was not to provide a statistically significant determination of the prevalence of animal abuse in violent households, all of the responses are combined in the overall figures and analysis. One of the women experienced abuse by both her son and partner, and one experienced abuse by her parents.

\section{Results}

All 23 women owned a pet or pets at the time they experienced abuse in the home.

Table 1: Experiences of threats or abuse of pet(s) $(\mathrm{N}=23)$

\begin{tabular}{|l|l|l|l|l|}
\hline $\begin{array}{l}\text { Responses of women and children } \\
\text { to their experiences of threats or } \\
\text { abuse }\end{array}$ & Yes & No & N/A & Total \\
\hline $\begin{array}{l}\text { Woman witnessed threats of } \\
\text { abuse to pet }\end{array}$ & 12 & 10 & 1 & 23 \\
\hline $\begin{array}{l}\text { Woman witnessed actual abuse } \\
\text { of pet }\end{array}$ & 11 & 10 & 2 & 23 \\
\hline $\begin{array}{l}\text { Children in household witnessed } \\
\text { threats against pet }\end{array}$ & 10 & 10 & 3 & 23 \\
\hline $\begin{array}{l}\text { Children in household witnessed } \\
\text { actual abuse of pet }\end{array}$ & 8 & 11 & 4 & 23 \\
\hline
\end{tabular}

Fifty six per cent of the 23 women in the study said they witnessed either threats, or actual abuse of their companion animal, with $50 \%$ indicating that their children had also witnessed threats or abuse (Table 1). However, it is impossible to assess the severity of the abuse observed by the latter group, as no children were interviewed in this study. Women described the threats they or their children witnessed as follows:

"He would threaten to kill the dog in front of both myself and the children." 
"In front of the children he would talk about giving the dog away, or worse still about killing him. This made the children very frightened as they loved the dog."

The animals that were abused experienced either physical abuse or neglect, with no reports of sexual abuse recorded. Figure 1 gives a breakdown of the forms of physical abuse to the animals.

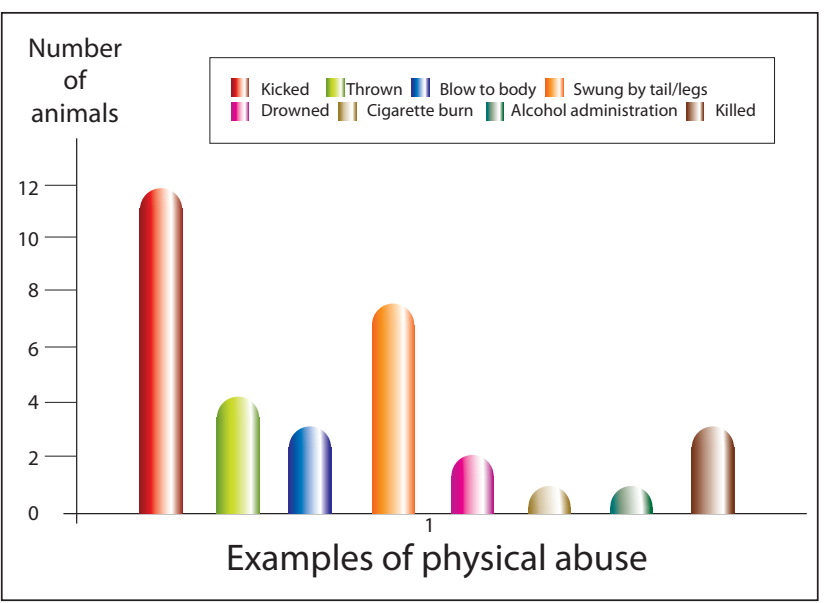

Figure 1: Forms of physical abuse experienced by animals in households, where concurrent violence to the woman by her partner occurred.

Women gave the following examples of physical abuse of their pets:

"I can remember an instance when he picked the cat up and with full force drop-kicked it from the back door. He did it because he saw the cat on the worktop. I thought the cat might die."

"He kicked the dog repeatedly until it was howling in pain."

"He put his hand into the goldfish bowl in front of my five-year-old daughter and squashed the goldfish, for no apparent reason.”

In five families, companion animals were neglected; five were denied food, one animal was denied access to exercise/ outdoors, and two were denied shelter. The women gave examples of such forms of abuse:

"He would refuse to allow us to feed the dog - saying he was ugly."

"He would not allow me to feed the dog, even if the food was there."

\section{Perceived motivations for abuse}

Of the 13 women who experienced threats/abuse of their pet, 12 women believed that their pets were used as a form of control over either, themselves or their children, with the remaining woman leaving this question unanswered (Figure 2).
The women were asked to ascribe what they felt was the motivation for the threats/abuse. The majority of participants selected more than one possible motivating factor.

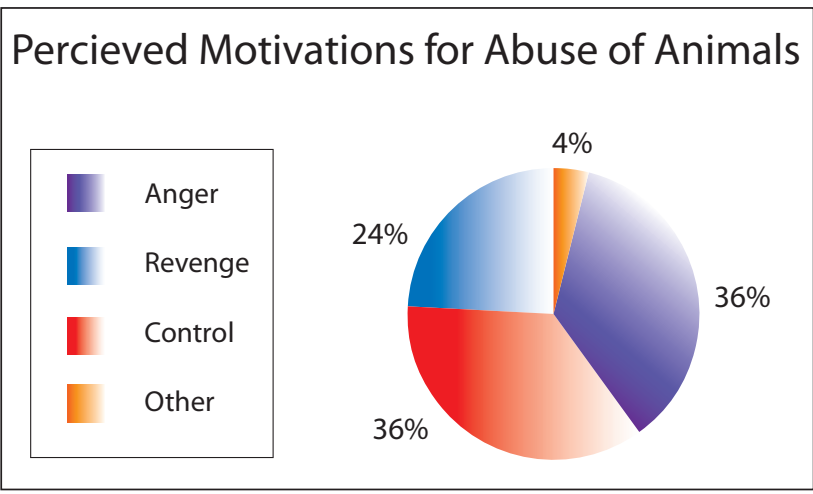

Figure 2: Perceived motivations for abuse of the household pets.

Commonly cited motivations for the abuse of their pets included anger and revenge, but the majority felt that even these motivations were simply another form of control. Control was identified as the principal motivation for abuse by $92.3 \%$ of respondents:

"He taunted me that if he could kill the dog, he could kill anything."

Revenge was also suspected as the cause of the abuse:

"My partner contacted me after I left, whilst still in the refuge to tell me that he had killed my dog, a dog I loved and had trained. He alleged that he had drowned him in a bog hole."

Such actions and comments have the implication that he was punishing the woman for leaving him, and that he was potentially capable of severe cruelty.

\section{Effects of animal abuse on women}

Of the 13 women experiencing either threats and/or abuse of their pet, four admitted that they had delayed seeking shelter in the refuge because of concerns for their pet(s):

"Fears for my pets caused me to stay for years."

"I delayed leaving for about five years. If a facility had been in place for my pets, I really would feel I could have left years before."

"I delayed leaving by months, until I found a safe home for my dog."

Only three of the 13 women who experienced both domestic violence and animal abuse reported their willingness to discuss their concerns regarding their pets with someone. Veterinary practitioners were not considered as a possible support group: 
"I was afraid that everybody would say, 'Don't be worrying about the dog, you should look after yourself."

The overall feeling of this group of women was that fears for a pet was an issue that could not be raised with either the refuge staff or even their own family:

"Pets were never discussed in the refuge, and I was afraid to send any member of my family to collect the animals.”

\section{Need for animal facilities}

In response to a question regarding the usefulness of having a facility for their companion animals when they have to leave the family home, of the 13 who had witnessed threats or actual abuse, 11 replied that they would have found such a facility helpful. Interestingly, two out of 10 women who had not witnessed such threats or abuse of their pets, felt this service would have made leaving their home easier for either themselves or their children. One woman admitted that she had returned home on a number of occasions, even though there was no history of pet abuse, because the children missed their dog. The responses of women to the availability of pet care facilities is shown in Table 2 .

Table 2: Responses of women to the availability of pet care facilities

Peace of mind for children - knowing their pet is safe

Peace of mind for women - knowing their pet is safe

Less worry, pressure and stress for women

7

Would have left home and partner earlier

Pet may not have been killed by abuser before she left home

\section{Discussion}

The findings of this study confirm the work of Ascione (1998), Arkow (1999), Flynn (2000) and Faver and Strand (2003), which has previously identified the interconnection of the abuse of women, and the intentional abuse of companion animals. Many of the aforementioned authors also identify a link between domestic violence and child abuse, or child abuse and animal abuse. In a recent study in Ireland by McGuinness et al. (2005), 46.6\% of the veterinarians surveyed suspect that the NAI they identified was part of a "wider spectrum of abuse within the home". The respondents in this present study have clearly identified that, in their experience, the primary purpose of animal abuse in their case was to control and manipulate them. This is not an unexpected finding as - consistent with previously published studies - control also plays a pivotal role in the dynamics of domestic violence (McGee, 2001; Marsden, 2001). As Marsden (2001) points out, animals are likely to be one of the instruments used in this abusive control. McGee (2001) made the point that other forms of violence, including physical violence, usually serve to reinforce the man's power and control over his partner.
Arkow (1999) drew parallels between the motivations and forms of abuse recognised in child, spousal and animal abusers. He discussed their desire to objectify their victims, an emotion echoed by a respondent in McGee's (2001) research,who, when asked about the control her partner exerted over her, stated:

"He wants to own you, you are a possession. You belong to him."

Arkow (1999) further stated that abusers of women, children or animals are most often physically stronger, leaving their victim unable to defend themselves, commonly expect unachievable standards from their victims, and feel physical punishment can be justified. More often than not, they show no empathy for their victims. The mechanism by which the abuse of companion animals in the family home can contribute to the ongoing control of women by their intimate partners, may be useful to an analysis of domestic violence that will be helpful in assessments of such violence by social service and health care professionals.

Kelly (1994) refers to the concept of "double level of intentionality" which she describes as "an act directed against one individual, is at the same time intended to affect another or others". The 'individual' against whom the violence is directed can be her children, her pets or other family members, and Kelly discusses this relationship in the context of domestic violence and child abuse. The findings of this study, as outlined above, would suggest that this double level of intentionality can also be applied to animal abuse.

The abuse of animals in the context of the abuse of women can be effective in three ways; firstly, by involving the feelings and fears of children and using these to coerce their mother. The numbers of women who reported that their children witnessed both threats and actual abuse of their pets evidences this involvement. Five women also stated that their partner threatened or abused their pets with their children present, therefore making it harder for her to leave unless the animal could be taken too:

"He told me that he would kill all the pets and tell the children that it was my fault. This made it hard for me to leave, as one child would always insist on staying with the animals."

Secondly, as has been pointed out by Faver and Strand (2003), the women's emotional attachment to the pet can be used as a means of instilling fear. Knowing that the welfare of the pet mattered to his partner, one woman reported that "he would hit the dog if he was annoyed with me", and as has been discussed above, fears for their pets safety serve to keep women in the relationship longer than they otherwise would. One of the women whose pet was killed by her partner stated:

"He waited until I became attached to the dog. Then he killed it."

As McGee (2001) notes, in discussing the abuse of property 
and possessions, "women were very hurt by what they felt these acts of destruction meant, particularly when items of particular sentimental value were destroyed". A pet animal is usually a child's, and often a woman's, most important possession.

The third pathway by which these dual forms of abuse function to control women, is by direct intimidation and the suggestion that the abuse of the pet is simply a foretaste of the violence of which he is capable:

"If he was angry with the pets I knew he would take his anger out on me too."

It is recognised that the most dangerous time for a woman is when she seeks help, or leaves the violent relationship. (Wilson and Daly, 1993). Sev'er (1997) suggested that separation presents a "six fold increase in risk to women", illustrated by the case of the woman in this survey whose pet was killed by her partner who stated:

"He killed her dog in retaliation because of her going to the refuge."

One of the most disturbing findings of this study was the almost unanimous reluctance of most of the women to discuss their fears for their pets with anyone. Only three of the 13 women, who experienced both domestic violence and animal abuse, reported their willingness to discuss concerns with someone. McGee, (2001) stated that loss of self-esteem and self-confidence are common psychological findings in sufferers of domestic violence. As a result, it is possible that not only did many of the women lack the confidence to raise the issue of pet abuse, but also this issue is not commonly broached by any of the professionals from whom abused women in Ireland seek assistance.

\section{Implications of these connections}

One of the challenges for professionals and the staff of counselling organisations and hospitals, who meet with women who are experiencing abuse, is to find ways to help abused women to identify the forms and degrees of abuse they may be experiencing.

Veterinary practitioners have the potential 'to be involved' because of their role in caring for the health and welfare of pets, including those of abused clients. Veterinary practitioners must be aware of aspects of abuse, and the interaction between animal and human abuse, and domestic violence. Recent literature, which suggests a distinction between "common couple violence" and "patriarchal terrorism", highlights that it is women experiencing the latter form of domestic abuse who are most likely to be found in such social, medical, or legal agencies (Johnson, 1995). An ability to ask appropriate questions and make accurate assessments is a key to helpful interventions. The growing recognition of the co-occurrence of child and woman abuse (Stark \& Flitcraft, 1988; Kelly, 1994; Edelson, 1999) is leading social workers and others to look for violence against women in cases of child abuse or neglect. Staff members in the refuges interviewed made the point that, if animal abuse can indicate other forms of family violence, then this information is relevant if a male partner, who is domestically violent, seeks custody of his children.

Findings such as those detailed in this study, and those of Ascione (1998, 1999), Flynn (2000) and Faver and Strand (2003) makes a strong case for the inclusion of appropriate questions about pets in domestic violence assessments. Encouraging women to recount their narrative of the treatment of their companion animals may serve two functions; firstly by providing an insight into the level of control and intimidation occurring in their intimate relationship, and secondly by acknowledging that their concerns for their pets are legitimate, and have the potential to be a factor inhibiting their freedom of movement. Veterinary practitioners too should be able to recognise signs suggesting abuse if asked to interview owners, and examine animals from a household where abuse could be occurring.

Such questions could also be helpfully included in the intake interviews of women by refuge staff. As discussed above, no Irish refuge currently has a facility for the care of pets and questions regarding pets are not included in the intake questionnaire. The refuge staff involved in the planning of this study recognised that, until the discussions that took place during its preparation, they were generally unaware of the significance of animal abuse in the lives of their clients. They realised that they had given the matter very little thought and most veterinary practitioners would be in a similar position. However, they were able to recall several instances where women were either prevented from coming to the refuge because of concern for their pet, or returned home to avoid their pets being harmed at the hands of their abusive partners.

Services such as that provided by Paws for Kids, First Strike in Britain, or Crosstrails, the animal fostering service described by Kogan et al. (2004), would appear to be a growing trend in an all-round refuge and support service for women and children. However, as the refuge staff pointed out in this study, without adequate resources for sufficient beds, or child counselling services, in their refuges, it is unlikely to be their priority in the foreseeable future. Responsibility for providing enhanced safety and services for women do not rest only with refuge providers. It will not require enhanced resourcing for social workers, and other professionals, to take into account women's, often unspoken, fears for their and their children's pets. Veterinarians have a role here if asked if they can support temporary homing, or provide accommodation for a pet of a client in a refuge.

When advice is sought on leaving a violent home, unanimity is required from agencies such as refuges, Women's Aid and the Gardaí regarding protocol for the safe removal of family pets. At present, the most 
appropriate legal advice that can be given is that, at the time of leaving, the woman herself should remove the animal. Such a move is imperative as the Protection of Animals Act, 1911, only provides for animals that have suffered offences of cruelty, not threats of cruelty. As a result, there is no support for the removal of any animal from its home by animal welfare organisations or the Gardai, unless it is actually being mistreated. Accordingly, no provision is made for women who feel their pet is in danger, under threat, or at risk of a retaliatory gesture for them leaving the home. This extremely frustrating and unhelpful aspect of the equivalent act in the UK has been reviewed and amended. It is our hope that Irish legislation will undergo review and amendment to increase its effectiveness in safeguarding the animals it was written to protect.

Despite the expansion and developments in the provision of services for abused women over the past two decades in Ireland, it is discouraging to hear from participants in this study that there are still no options available for the care of pets who are not only targets of abuse, but also important sources of comfort for both women and children. This deficiency is present for a number of reasons including the fact that Irish refuges are faced with ongoing financial challenges due to lack of funding, especially for any new initiatives. But, ultimately, the most significant obstacle for such a development is lack of awareness of the 'link' between helpline workers, refuge workers, doctors, social workers, the police, animal welfare officers and veterinary practitioners.

At present, veterinary practitioners graduating and working in Ireland receive little formal education on the pervasiveness of NAI of animals, or abuse of animals in association with domestic violence, serious violent crime and other anti-social behaviour. As a result, they are unsure of how to recognise or deal with such incidences (McGuinness et al., 2005). A survey carried out in 31 veterinary medical schools in both Canada and the US revealed that $97 \%$ and $63 \%$ of respondents respectivly felt that they would encounter incidents of animal and human abuse respectively at some stage in their career. Eighty per cent of these respondents believed that this abuse can be interconnected, but only $75 \%$ of school curricula address the issue of animal abuse and methods for its reporting. Only $21 \%$ of these schools discussed the recognition of human abuse, the implications and the protocols for reporting such abuse in that particular state (Landau, 1999). In 1993, the state of Minnesota introduced legislation that mandates all practising veterinarians to report inhumane treatment of animals to law enforcement officers or humane officers, or face charges of non-professional conduct (Reisman \& Adams, 1999). Such mandates are controversial, with arguments for and against their impact on the veterinary profession, as discussed by Arkow (1994) and Douglas (2000). Despite the challenges for veterinary practitioners who are faced with NAI and its proven connection to interpersonal violence, it is still clear that the role of veterinary practitioners and their future contribution to this societal problem is vital in the prevention of such violence and for provision of assistance when domestic violence occurs.

\section{Recommendations}

Many of the recommendations from the findings of this study, which are relevant to social service organisations, but there are several that can be made for veterinary practitioners:

- the Animal's Protection Act 1911 should be reviewed to address the issue of potential violence to an animal. Veterinary practitioner input and analysis would be essential for any such review;

- veterinary practitioners, social workers and the Gardaí must be fully aware of the close association between domestic violence and animal abuse, and work together to support victims, and to educate the public on the association;

- education of veterinary practitioners on how to recognise, the often subtle signs of animal and domestic violence is paramount;

- veterinary practitioners have a role in supporting refuges, which may have occupants who require care for their pets, or they need immediate or temporary accommodation for their family pet;

- veterinary practitioners could create a network or support service that could work with refuges to support abused pets and help the refuge occupants; and,

- veterinary practitioners are part of the network of support for dealing with the results of domestic violence as pet animals are involved, and their health and welfare are our responsibility.

\section{Acknowledgements}

This research would not have been possible without the participation of the women who shared very personal information in often very stressful circumstances. These women were motivated by the desire to help those who are in similar position to themselves, and to highlight a topic that is currently unexplored in Ireland. The authors also thank the staff from each refuge centre whose help enabled the study to be conducted. Despite the nature of the research topic, they were enthusiastic in their willingness to explore the significance of the abuse of companion animals and domestic violence. This project increased their already heavy workload, as they offered counselling and support to those women who participated. The authors thank their sponsors; Intervet (Ireland) Ltd and the Veterinary Council of Ireland for making this project possible. 


\section{References}

Arkow, P. (1992). The correlations between cruelty to animals and child abuse, and the implications for veterinary medicine. The Canadian Veterinary Journal 33: 518-521.

Arkow, P. (1994). Child abuse, animal abuse, and the veterinarian. The Journal of the American Veterinary Medical Association 204: 1004-1007.

Arkow, P. (1996). The relationships between animal abuse and other forms of family violence. Family Violence and Sexual Assault Bulletin 12: 29-34.

Arkow, P. (1999). The Evolution of Animal Welfare as a human welfare concern. In: Child Abuse, Domestic Violence and Animal Abuse. Pp19-37. Edited by F. R. Ascione and P. Arkow. United States of America: Purdue Research Foundation.

Ascione, F.R. (1998). Battered womens' reports of their partners' and their children's cruelty to animals. Journal of Emotional Abuse 1: 119-133.

Ascione, F.R. (1999). The abuse of animals and human interpersonal violence - Making the connection. In: Child Abuse, Domestic Violence and Animal Abuse. Pp 50-61. Edited by F. R. Ascione and P. Arkow. United States of America: Purdue Research Foundation.

Bradley, F. (2002). Reported frequency of domestic violence: Cross sectional survey of women attending general practice. British Medical Journal 324: 271-274.

Bustad, L.K. (1996). Prison programs involving animals. In: Compassion: Our last great hope. Pp 71-80. Edited by L.K. Bustad. United States of America: Delta Society.

DeViney, E.J., Dickert, J. and Lockwood, R. (1983). The care of pets within child abusing families. International Journal for the Study of Animal Problems. 4: 321-329.

Dobash, R.E. and R.P. Dobash. (1992). Women, Violence and Social Change. London: Routledge.

Douglas, J.C. (2000). Horns of dilemma: The vetri-legal implications of animal abuse. Canadian Veterinary Journal 41: 715-720.

Edelson, J.L. (1999). The overlap between child maltreatment and woman battering. Violence Against Women 5: 134-154.

European Women's Lobby (EWL) (2004). Press Release. [Online] http://www.womenslobby.org Accessed on February 2, 2005.

Faver, C.A. and Strand, E.B. (2003). Domestic violence and animal cruelty: Untangling the web of abuse. Journal of Social Work Education 39: 237-53.

Flynn, C.P. (2000). Woman's best friend: Pet abuse and the role of companion animals in the lives of battered women. Violence Against Women 6: 162-177. Gelles, R.J. (1997.) Intimate Violence in Families. Third Edition. London: Sage.

Johnson, M.P (1995). Patriarchal terrorism and common couple violence: two forms of violence against women. Journal of Marriage and the Family 57: 28.

Johnson, M.P. and Ferraro, K.J. (2000). Research on domestic violence in the 1990's: making distinctions. Journal of Marriage and the Family 62: 948-963.

Kelleher, P. and O'Connor, M. (1995). Violence against women in intimate relationships with men. In: Making the Links. Dublin: Women's Aid.

Kellert, S.R. and Felthouse, A.R. (1985). Childhood cruelty towards animals among criminals and noncriminals. Human Relations 38: 113-29.

Kelly, E. (1994). The interconnectedness of domestic violence and child abuse. Challenges for research, policy and practice. In: Children Living with Domestic Violence: Putting Men's Abuse of Women on the Child Care Agenda. Edited by A. Mullender and R. Morle. London: Whiting and Birch.

Kimmel, M.S. (2002). "Gender Symmetry" in Domestic Violence. Violence against women 8: 1332-1363.

Kogan, L.R., S. McConnell, Schoenfeld-Tacher, R. and Jansen-Lock, P. (2004). Crosstrails. Violence Against Women 10: 418-434.

Landau, R. (1999). The veterinarians' role in recognizing and reporting abuse. In: Child Abuse, Domestic Violence and Animal Abuse. Pp 241-249. Edited by F. R. Ascione and P. Arkow. United States of America: Purdue Research Foundation.

Marsden, C. (2001). Saving lives - intervention that really works. In: Forging The Link. Pp 33-36. Edited by H. Cook. United Kingdom: Intervet.

Marsden C. (1997). In: PAWS for Kids [Online] Available from: http://www. pawsforkids.org.uk Accessed 12 June 2003.

McGee, C. (2001). Childhood Experiences of Domestic Violence. Second edition. United Kingdom: Jessica Kingsley Publishers Ltd.

McGuinness, K., Allen, M. and Jones, B.R. (2005) Non-accidental injury in companion animals in the republic of Ireland. Irish Veterinary Journal 58: 392-395.

Munro, H.M.C. and Thrusfield, M.V. (2001). 'Battered pets': features that raise suspicion of non-accidental injury. Journal of Small Animal Practice
42: 218-226.

Pence, E. and Paymar, M. (1987). Education groups for men who batter: The Duluth model. Pp12 New York: Springer.

Reisman, R. and Adams, C.A. (1999). Should veterinarians tell? In: Child Abuse, Domestic Violence and Animal Abuse. Pp 221-227. Edited by F. R. Ascione and P. Arkow. United States of America: Purdue Research Foundation.

Royal Society for the Prevention of Cruelty to Animals, (2003). Annual Review of Inspectorate statistics. Pp 11. Edited by A. Bailey, S. Corrall and S. Evans. UK: Spin Offset Limited.

Sev'er, A. (1997). Recent or imminent separation and intimate violence against women: a conceptual overview and some Canadian examples. Violence Against Women 3: 566-589.

Stark, E.A. and Flitcraft, A. (1988). Women and children at risk: A feminis perspective on child abuse. International Journal of Health Services 18: 97-118.

Stark, E \& A. and Flitcraft, A. (1996). Women at Risk: Domestic Violence and Women's Health. London: Sage.

Strauss, M.A. and Gelles, R.J. (1990). Physical violence in American families: Risk factors and adaptation to violence in 8,145 American families. New Brunswick: Transaction.

Wilson, M. and Daly, M. (1993). Spousal homicide risk and estrangement.

Violence and Victims 8: 3-16. 